\title{
Workplace bullying among nurses working in tertiary hospitals in Enugu, southeast Nigeria: Implications for health workers and job performance
}

\author{
Ada C. Nwaneri ${ }^{1}$, Amara C. Onoka ${ }^{* 1}$, Chima A. Onoka ${ }^{2}$ \\ ${ }^{1}$ Department of Nursing, University of Nigeria, Enugu, Nigeria \\ ${ }^{2}$ Department of Community Medicine, College of Medicine, University of Nigeria Teaching Hospital, Enugu, Nigeria
}

Received: June 22, 2016

Accepted: September 1, $2016 \quad$ Online Published: September 26, 2016

DOI: $10.5430 /$ jnep.v7n2p69

URL: http://dx.doi.org/10.5430/jnep.v7n2p69

\begin{abstract}
Background: Workplace bullying among nurses has been identified as a major contributor to poor attitude towards duties, and reduction in overall productivity. This study examined the occurrence and effects of behaviors that constitute workplace bullying among nurses in tertiary hospitals in Enugu, Southeast Nigeria.

Methods: Data were collected from 286 nurses working in 4 tertiary hospitals in Enugu State, Southeast, Nigeria, using a modified 22-item Negative Acts Questionnaire (NAQ) for measuring bullying behaviors in the workplace, and a 26-item General Health Questionnaire (GHQ) for measuring the impact of bullying.

Results: The prevalence of workplace bullying among nurses working in tertiary hospitals in Enugu is reported to be high. Data provided by the respondents in relation to prevalence was greatly affected by poor knowledge of what constitutes workplace bullying among nurses. A total of $82.6 \%$ of the respondents reported that they have been victims of workplace bullying. Behaviors observed most (on daily basis) over the 6-month period preceding the study include gossiping (22.0\%), backbiting (18.7\%), excessive workload without supervision (17.3\%), failure to respect privacy (13.1\%), intimidation (12.6\%), humiliating someone in front of others including patients (12.1\%) and unfair allocation of job and postings (8.4\%). The main perpetrators of workplace bullying were identified by $76 \%$ of the respondents as senior nurses overseeing hospital wards/units, $84.1 \%$ of the respondents also indicated that nurses in junior cadre were the main targets. Female nurses were identified as the main perpetrators and targets of workplace bullying among nurses by $93.9 \%$ and $92.1 \%$ of the respondents respectively. The reported impact of workplace bullying among nurses include anger (50.5\%), an intention to travel abroad because of the feeling that the prevalence is less there $(33.6 \%)$, anxiety $(21.5 \%)$, frustration $(16.8 \%)$ and strained social relationships amongst colleagues $(11.2 \%)$.

Conclusions: Workplace bullying (mainly from senior nurses to junior ones) is highly prevalent and has significant impact on the health, job performance and retention rate of nurses working in tertiary hospitals in Enugu. Poor knowledge of what constitutes workplace bullying among nurses, relational aggression and female oppression have great implication in the prevalence, nature of bullying behaviors exhibited, characteristics of the perpetrators and the outcome of workplace bullying among the nurses. In order to reduce the prevalence of workplace bullying among nurses working in tertiary hospitals in Enugu, the nurses do not only require education on what constitutes workplace bullying, they also need adequate information about how to communicate respectfully with each other in the workplace. Nurse leaders and hospital administrators should also constitute disciplinary committees, encourage nurses to report the incidence of workplace bullying, punish perpetrators as well as protect those who report the cases from further attacks of bullying through establishment of policies to regulate interpersonal relationships among nurses.
\end{abstract}

Key Words: Workplace bullying, Oppression, Relational aggression, Nursing, Nigeria, Prevalence, Impact, Negative behaviors, Negative acts questionnaire, Senior nurses, Junior nurses, Nursing culture

*Correspondence: Amara C. Onoka; Email: amaraonoka@gmail.com; Address: Department of Nursing, University of Nigeria, Enugu, Nigeria. 


\section{INTRODUCTION}

Health workers perform better when a harmonious working environment exists within and across groups of health professionals. Specifically workplace bullying, which negatively impacts on health workers performance, has been identified as a major problem among nurses in many hospitals. ${ }^{[1]}$ Studies show that workplace bullying is more widespread among nurses than among members of other health profession. ${ }^{[2]}$ Its prevalence can range from $43 \%$ reported in a UK study $^{[3]}$ to $85 \%$ reported in a statewide survey done in the USA. ${ }^{[4]}$ Its existence has remarkable effects on the nurse, the quality of care s/he offers, the effectiveness of the healthcare organization as well as the nursing profession. ${ }^{[5]}$ Many definitions that highlight the characteristics of workplace bullying among nurses have been proffered. The Centre for American Nurses defines it as an offensive, abusive, intimidating, insulting behavior or abuse of power exhibited by one nurse towards another, which makes the recipient feel upset, humiliated or vulnerable, undermines her self-confidence and may cause her stress. ${ }^{[6]}$ Workplace bullying is also defined as a situation where a nurse feels that she has repeatedly been on the receiving end of negative actions from one or more other nurses, in a situation where it is difficult to defend herself against these actions. ${ }^{[7]}$ These definitions point out the subjective nature of workplace bullying as well as its major characteristics: duration, frequency (occurring daily or weekly for at least 6 months), attributed intent, escalation and power disparity. ${ }^{[8]}$

Workplace bullying can be overt or covert as well as physical (involving direct bodily contact with the target such as hitting and slapping), verbal (involving use of words such as gossiping and shouting), and cyber (through letters, text messages and social media). ${ }^{[9]}$ The 10 most common forms of workplace bullying behaviors among nurses are; non-verbal innuendo, verbal insult, undermining activities, with-holding information, sabotage, infighting, scape-goating, backstabbing, failure to respect privacy and broken confidences. ${ }^{[5]}$ In Nigeria, the most commonly observed workplace bullying behaviors among nurses were manipulation of duty schedule, back-biting, gossiping, poor interpersonal relationships and unfair allocation of jobs and postings. ${ }^{[10]}$ Many factors have been associated with the high prevalence of workplace bullying among nurses. The two main factors are relational aggression (which is closely associated with the female gender) and oppression. Firstly, females have an inherent tendency to bully other females because of the effects of relational aggression and male oppression. ${ }^{[11,12]}$ Relational aggression which is psychological aspects of bullying naturally predisposes females to exhibit such behaviors like gossiping, formation of social cliques, intimidation, social exclusion etc. To sup- port these statements, reports from a survey carried out in the US revealed that in 57\% of the cases, women are subjects of bullying by males while fellow women are usually targets of bullying when a woman is the bully in $71 \%$ of cases. ${ }^{[11]}$ This is because oppressed persons lack the power to fight their oppressors; they turn around and fight those of lesser power. ${ }^{[13]}$ Florynce Kennedy ${ }^{[12]}$ therefore concluded that oppressed people are very oppressive. The effect of relational aggression and oppression probably explains the high prevalence of workplace bullying in nursing which a female dominated profession.

Other causes of workplace bullying among nurses are individual factors (domineering personality, mental illness, age differences), organizational factors (organizational tolerance of bullying) ${ }^{[14]}$ and professional factors (female dominance of nursing, hierarchy, culture of silence). ${ }^{[14]}$ Females and nurse managers have been identified by most authors as the main perpetrators of these behaviors in $83 \%$ and $71 \%$ of the cases respectively. ${ }^{[15]}$ It is also reported that female junior nurses are the main targets and victims as well.

The consequences of workplace bullying can be profound. Notably, it is a major reason why nurses leave their profession. ${ }^{[16]}$ Some reactions in response to bullying include anger, weight loss/gain, low self-esteem, altered sleep patterns, alcoholism and strained social and work relationships among team members. ${ }^{[5,17]}$ These reactions impact negatively on a nurse's health and workplace service delivery. Oftentimes, the poor image attributable to bullying behaviors among nurses, results to their inadequate representation in hospital management teams. ${ }^{[2]}$

The consequences of workplace bullying among nurses have stimulated research in most developed countries and interest in establishing measures to control it. ${ }^{[18]}$ Suggested ways of improving interpersonal relationships among nurses include; provision of training regarding communication skills, coaching and mentoring of all nurses with regard to fostering healthy interpersonal communication among them. ${ }^{[19]}$ Also suggested are mediation services in instances of unresolved disputes between parties and punishment for perpetrators. However, such efforts to control the behavior are largely observed in developed countries. ${ }^{[14]}$

Given the paucity of evidence on workplace bullying in Nigeria, this study that was undertaken among registered nurses working in tertiary hospitals in Enugu State, Southeast Nigeria, determined; the occurrence, perpetrators, targets and the effects of workplace bullying behaviors on victims. The analyses provide relevant evidence on the need to establish policies and measures to reduce the incidence of workplace bullying among nurses. 


\section{MeTHODS}

\subsection{Area of study}

This cross-sectional descriptive study took place in Enugu State, southeast Nigeria. The state occupies a land mass of $7,161 \mathrm{~km}^{2}$ and had a projected population of 3.8 million in 2012. ${ }^{[20]}$ The state capital Enugu has four tertiary health facilities that receive patients from within and beyond the south-eastern region of Nigeria, and especially from Enugu State.

\subsection{Sample}

The hospitals had a total of 1,415 registered nurses and 73 wards/units (Staff statistics from the four hospitals, 2014), which were grouped as outpatient units, medical wards, surgical wards and theatre. Nurses at various levels were grouped as; junior cadre (Nursing Officers I and II), middle cadre (Senior Nursing Officers, Principal Nursing Officers and Assistant Chief Nursing Officer) and senior cadre (Chief Nursing Officers, Assistant Directors of Nursing Services and Heads/Directors of Nursing Services).

\subsection{Data collection}

The study involved collection of information from 259 registered nurses, selected by using a proportionate stratified sampling technique. The design considered the number of nurses in the four existing tertiary hospitals in Enugu State and their distribution across the four groups of wards. Adequate sample size was computed based on a prevalence of $75 \%$ for occurrence of workplace bullying that was determined in a related study. ${ }^{[18]}$ Questionnaires were distributed and mailed to the respondents in the 4 hospitals by the researcher and 5 trained assistants. Data collection lasted for five (5) weeks. A return rate of $91 \%$ was recorded.

\subsection{Questionnaire}

The survey questionnaire includes a 22-item modified Negative Acts Questionnaire (NAQ), a 26-item General Health Questionnaire (GHQ), in addition to other relevant questions to the study. The NAQ is a standardized tool consisting of 22 questions originally created to measure the frequency, intensity and prevalence of workplace bullying and harassment in any work setting. In the modified NAQ, the terms "workplace bullying" or "harassment" is never used rather respondents are asked how often they have experienced any of the 22 behaviorally defined negative acts listed on the modified NAQ within the 6-month period preceding to the study. The questionnaire was in 2 sections, the first section sought to obtain information about the socio-demographic information and general question about the prevalence of workplace bullying while the second section contains the modified NAQ and the GHQ. Frequency of experience of the negative acts is rated by the participant in a likert scale ranging from 0 (never), 1 (occasionally), 2 (monthly), 3 (weekly) and 4 (daily). The reliability and validity of the NAQ have been well established with Cronbach alpha scores ranging from 0.87-0.93 in various research studies. ${ }^{[1]}$ In addition, a 26-item GHQ was used to assess the impact of workplace bullying on the respondents using a likert scale ranging from 0(strongly disagree), 1 (disagree), 2 (undecided), 3 (agree) and 4 (strongly agree). Using the questionnaire, the respondents also indicated whether workplace bullying existed in their hospitals, who the main perpetrators and targets are and the influences of workplace bullying on them.

\subsection{Validity and reliability tests}

The questionnaire was piloted with a convenience sample of 29 nurses at Federal Teaching Hospital, Abakaliki, Ebonyi State which is also a tertiary hospital in a neighboring state. Minor changes were made in the wording and format to adapt the questions to the context.

\subsection{Ethical considerations}

Ethical guidelines of voluntary participation, informed consent and the possibility of withdrawal at any point were followed. Participants were also informed about the purpose and aim of the study. All information given by the respondents were also made anonymous. Ethical permission was obtained from the Research Ethics Committees of the Enugu State University Teaching Hospital and the University of Nigeria Teaching Hospital, Enugu.

\subsection{Data analysis}

Data were analysed using SPSS version 20.0 and involved computation of simple descriptive statistics including mean scores and standard deviations. Decision rules were used to aggregate observations about behaviors that constitute workplace bullying and their effects on the respondents.

The occurrence of workplace bullying was analysed using two approaches. Firstly, based on the indication (yes/no) of existence of workplace bullying among nurses either as a victim, target or witness in the respondents' hospital, ward/unit and secondly, based on the respondents' actual experience of workplace bullying as listed on the modified NAQ. The prevalence of workplace bullying was estimated by considering the number (and percentage) of respondents that experienced the occurrence of at least one negative behavior listed in the modified NAQ, within the period of six months preceding the study. ${ }^{[3,21]}$ The distribution of the experience of such behaviors among these respondents (daily, weekly, monthly or occasionally) was then determined. The most frequently experienced behavior was taken to be the behavior with the highest occurrence on daily basis. 
The intensity of workplace bullying which measures how problematic the issue is was determined as the sum of negative acts that subjects experienced more often than "never", i.e. seldom, sometimes and often. ${ }^{[1]}$ Additionally, the respondents' view of perpetrators and targets was analysed. In the text, a subject is considered a "target" of workplace bullying if he/she experienced at least 2 different negative acts daily or weekly. In the same vein, the subject is considered a "perpetrator" if he/she causes one or more other nurses to feel that they have repeatedly been on the receiving end of negative actions in a situation where it is difficult for the nurse or nurses to defend herself or themselves. ${ }^{[7,9]}$

The impact of workplace bullying on nurses was examined by allowing respondents to state the extent (strongly disagree, disagree, undecided, agree and disagree) to which they experienced specified outcomes of workplace bullying as listed on the GHQ.

\section{RESUlts}

\subsection{Socio-demographic characteristics of the respon- dents}

As shown in Table 1, most respondents were aged between 30-39 years. The respondents were mainly females $(90.3 \%)$ and married (69.5\%). Most had worked for 8-16 years. The respondents were of various specialties in nursing: 137 $(52.9 \%)$ are registered midwives, $6(2.3 \%)$ ophthalmic nurses, $2(0.8 \%)$ cardiothoracic nurses, $28(10.8 \%)$ were orthopaedic nurses, 35 (13.5\%) were psychiatric nurses and 9 (3.5\%) were public health nurses. Respondents from other specialties in nursing include $5(1.9 \%)$ paediatric nursing, $11(4.2 \%)$ peri-operative, $10(3.9 \%)$ are anaesthetic nurses, $10(3.9 \%)$ specialized in burns and plastic nursing and $6(2.3 \%)$ were intensive care nurses. From their responses, 61 (23.6\%) of the respondents indicated that they worked in the out-patient departments, 81 (31.3\%) worked in medical wards, 93 (35.9\%) worked in surgical wards while $24(9.3 \%)$ worked in the theatre.

\subsection{Workplace bullying as perceived by nurses}

Table 2 shows that 204 (78.8\%) respondents indicated that workplace bullying exists among nurses in their hospitals, $36(13.9 \%)$ said that it did not exist, $19(7.3 \%)$ were not sure if the trend existed among nurses in their hospitals. A total of $57(22 \%)$ of the respondents indicated negative to the question that sought to determine if workplace bullying among nurses existed in their wards. A total of 187 (72.2\%) responded in the affirmative and $15(5.8 \%)$ indicated that they were not sure if it existed in their wards/units.

Furthermore, $211(81.5 \%)$ said that they had witnessed the bullying of another nurse, 189 (73\%) of the respondents had actually been victims of workplace bullying among nurses. In addition, majority of the victims of workplace bullying $136(72 \%)$ did not report the bullying incident to a relevant authority.

Table 1. Socio-demographic characteristics of the respondents $(n=259)$

\begin{tabular}{lll}
\hline Variables & Frequency & Percentage (\%) \\
\hline Age & 38 & \\
$\quad<30$ & 138 & 53.7 \\
$30-39$ & 67 & 25.9 \\
$40-49$ & 16 & 6.2 \\
$\geq 50$ & & \\
Gender & 234 & 90.3 \\
$\quad$ Female & 25 & 9.7 \\
$\quad$ Male & & \\
Marital Status & 62 & 23.9 \\
$\quad$ Single & 180 & 69.5 \\
$\quad$ Married & 6 & 2.3 \\
Separated/divorced & 11 & 4.2 \\
$\quad$ Widowed & & \\
Work Experience (Years) & 89 & 34.4 \\
$\quad<8$ & 120 & 46.3 \\
$8-16$ & 41 & 15.8 \\
17-25 & 9 & 3.5 \\
$\geq 26$ & & \\
Professional Cadre & 105 & 40.5 \\
Junior (NS/NO II \& NO I) & & 53.3 \\
Middle (SNS/SNO, PNS/PNO \& & 138 & 6.2 \\
ACNS/ACNO) & 16 & \\
Senior (CNO, ADNS, DDNS/HNS & & \\
\hline
\end{tabular}

\subsection{Extent of daily experience of workplace bullying among nurses}

After a brief explanation of the term workplace bullying, the respondents were required to indicate to what extent they experienced the trend. Table 4 shows that 25 (11.7\%) of the respondents indicated that they often experienced workplace bullying among nurses ( $\geq 5$ times) in a week whereas a total of $195(75.3 \%)$ indicated sometimes, seldom and never. In addition, $203(78.4 \%)$ of the respondents reported that they witnessed the bullying of other nurses and only 29 (13.6\%) reported experiencing it often.

\subsection{Workplace bullying based on the Modified NAQ}

Of the 259 respondents, $214(82.6 \%)$ of the respondents indicated that they have observed one or more of the negative behaviors listed on the modified NAQ from one or more other nurses daily or weekly within the past six months. As shown in Table 3, gossiping occurred most frequently on daily basis $47(22.0 \%)$ while physically assaulting team members was not reported at all. Other behaviors observed frequently among nurses were backbiting 40 (18.7\%), excessive workload without supervision 37 (17.3\%), failure to 
respect privacy $28(13.1 \%)$, humiliating someone in front of $(8.4 \%)$ and $15(7.0 \%)$ of the respondents respectively while others including patients $27(12.6 \%)$, and unfair allocation of sending nasty text messages was rarely observed by 4 (1.9\%) job and postings 26 (12.1\%). Backstabbing and having one's of the respondents.

competence questioned were infrequently observed by 18

Table 2. Prevalence of workplace bullying (as perceived by nurses) among respondents ( $\mathrm{n}=259)$

\begin{tabular}{|c|c|c|c|}
\hline \multirow{2}{*}{ Questions } & Yes & No & Not sure \\
\hline & n (\%) & n (\%) & n (\%) \\
\hline Whether workplace bullying exists among nurses in the hospital & $204(78.8)$ & $36(19.9)$ & $19(7.3)$ \\
\hline Whether workplace bullying exists among nurses in respondent's ward/unit & $187(72.2)$ & $57(22)$ & $15(5.8)$ \\
\hline Whether respondent had witnessed bullying of a nurse by another nurse & $211(81.5)$ & $45(17.4)$ & $3(1.2)$ \\
\hline Whether respondent had been a victim of workplace bullying among nurses & $189(73)$ & $67(25.9)$ & $3(1.2)$ \\
\hline Victims of workplace bullying that reported the incident to the authorities among those that experienced it & $53(28)$ & $136(72)$ & NA \\
\hline
\end{tabular}

Table 3. Negative behaviors observed by nurses within the past six months $(\mathrm{n}=214)$

\begin{tabular}{|c|c|c|c|c|c|}
\hline Negative Behaviors & $\begin{array}{l}\text { Never } \\
\text { n (\%) }\end{array}$ & $\begin{array}{l}\text { Occasionall } \\
\text { y n (\%) }\end{array}$ & $\begin{array}{l}\text { Monthly } \\
\text { n (\%) }\end{array}$ & $\begin{array}{l}\text { Weekly } \\
\text { n (\%) }\end{array}$ & $\begin{array}{l}\text { Daily } \\
\text { n (\%) }\end{array}$ \\
\hline Gossiping & $26(12.1)$ & $107(50.0)$ & $7(3.3)$ & $27(12.6)$ & $47(22.0)$ \\
\hline Backbiting & $47(22.0)$ & $107(50.0)$ & $7(3.3)$ & $13(6.1)$ & $40(18.7)$ \\
\hline Excessive workload without supervision & $46(21.5)$ & $92(43.0)$ & $16(7.5)$ & $23(10.7)$ & 37 (17.3) \\
\hline Failure to respect privacy & $64(29.9)$ & $94(43.9)$ & $13(6.1)$ & $15(7.0)$ & $28(13.1)$ \\
\hline Humiliating someone in front of others including patients. & $43(20.1)$ & $102(47.7)$ & $12(5.6)$ & $30(14.0)$ & 27 (12.6) \\
\hline Unfair allocation of job and postings & $30(14.0)$ & $126(58.9)$ & $9(4.2)$ & $23(10.7)$ & $26(12.1)$ \\
\hline Backstabbing & $82(38.3)$ & $93(43.5)$ & $5(2.3)$ & $16(7.5)$ & $18(8.4)$ \\
\hline Having one's competence questioned & $50(23.4)$ & $120(56.1)$ & $14(6.5)$ & $15(7.0)$ & $15(7.0)$ \\
\hline Sabotage & $69(32.2)$ & $117(54.7)$ & $4(1.9)$ & $9(4.2)$ & $15(7.0)$ \\
\hline $\begin{array}{l}\text { Having key areas of responsibility removed and replaced with } \\
\text { trivial and/or unpleasant task }\end{array}$ & $78(36.4)$ & $97(45.3)$ & $12(5.6)$ & $14(6.5)$ & $13(6.1)$ \\
\hline Being intimidated with threatening behavior & $65(30.4)$ & $106(49.5)$ & $15(7.0)$ & $16(7.5)$ & $12(5.6)$ \\
\hline Ignoring attempts at conversation & $72(33.6)$ & 109 (50.9) & $9(4.2)$ & $13(6.1)$ & $11(5.1)$ \\
\hline Unfair manipulation of duty roster \&duty schedule & $38(17.8)$ & $114(53.3)$ & $23(10.7)$ & $28(13.1)$ & $11(5.1)$ \\
\hline Shouting/ verbal outbursts or verbal threats & $63(29.4)$ & $115(53.7)$ & $12(5.6)$ & $14(6.5)$ & $10(4.7)$ \\
\hline With-holding information necessary for patients' care & $135(63.1)$ & $59(27.6)$ & $3(1.4)$ & $7(3.3)$ & $10(4.7)$ \\
\hline Broken confidences & $56(26.2)$ & $121(56.5)$ & $21(9.8)$ & $7(3.3)$ & $9(4.2)$ \\
\hline Refusing to teach/mentor & 109 (50.9) & $80(37.4)$ & $10(4.7)$ & $6(2.8)$ & $9(4.2)$ \\
\hline Being excluded from the team & $103(48.1)$ & $79(36.9)$ & $5(2.3)$ & $19(8.9)$ & $8(3.7)$ \\
\hline Scape-goating & $106(49.5)$ & $87(40.7)$ & $7(3.3)$ & $6(2.8)$ & $8(3.7)$ \\
\hline Sending nasty text messages & $170(79.4)$ & $31(14.5)$ & $5(2.3)$ & $4(1.9)$ & $4(1.9)$ \\
\hline Physically assaulting team members & $209(97.7)$ & $3(1.4)$ & $2(0.93)$ & $0(0)$ & $0(0)$ \\
\hline
\end{tabular}

Table 4. Extent of weekly experience of workplace bullying among nurses working in tertiary institutions in Enugu State (n =214)

\begin{tabular}{llllll}
\hline \multirow{2}{*}{ Variable } & $\begin{array}{l}\text { Often } \\
\mathbf{5} \text { and above) }\end{array}$ & $\begin{array}{l}\text { Sometimes } \\
\mathbf{( 3 - 4} \text { times) }\end{array}$ & $\begin{array}{l}\text { Seldom } \\
\mathbf{( 1 - 2} \text { times) }\end{array}$ & Never & $\begin{array}{l}\text { Total (Seldom, } \\
\text { sometimes and often) }\end{array}$ \\
\cline { 2 - 6 } & $\mathbf{n ~ ( \% )}$ & $\mathbf{n ~ ( \% )}$ & $\mathbf{n ~ ( \% )}$ & $\mathbf{n ~ ( \% )}$ & $\mathbf{n ~ ( \% )}$ \\
\hline $\begin{array}{l}\text { How often respondents experience workplace } \\
\text { bullying in a week }\end{array}$ & $25(11.7)$ & $74(34.6)$ & $96(44.9)$ & $19(8.9)$ & $195(91.1 \%)$ \\
$\begin{array}{l}\text { How often respondents witness the bullying of } \\
\text { another nurse on a weekly basis }\end{array}$ & $29(13.6)$ & $105(49.1)$ & $69(32.2)$ & $11(5.1)$ & $203(94.9 \%)$ \\
\hline
\end{tabular}


3.5 Respondents' view of the characteristics of the main perpetrators and targets of workplace bullying among nurses

The respondents' description of the characteristics of the main perpetrators and targets of workplace bullying among nurses indicates that females were the main perpetrators 201 (93.9\%) as well as the main target $197(92.1 \%)$ of workplace bullying (see Table 5). On the other hand, 163 (76.2\%) of the respondents were of the view that nurses in senior cadre were the main perpetrators while $180(84.1 \%)$ indicated that nurses in junior cadre were the main targets.

\subsection{Impact of workplace bullying among nurses}

Table 6 shows that workplace bullying has significant impact on the general health, job performance and retention rate of the respondents who indicated that they had experienced the negative acts listed on the modified NAQ either as a targets/victims within the 6 months prior to the study. A total of $108(50.5 \%)$ of the respondents strongly agree that the experience of workplace bullying (either as a target or vic- tim) made them angry. In addition, $72(33.6 \%)$ wish to travel abroad to practice nursing because they felt that there will be less workplace bullying among nurses there. Other major impact which the respondents strongly agreed to were; anxiety $46(21.5 \%)$, frustration $36(16.8 \%)$ and an intention to leave nursing profession by $31(14.5 \%)$. In addition, 35 (16.4\%) of them indicated that it enabled them have better self-control in handling relationships with colleagues whereas 33 (15.4\%) indicated job dissatisfaction as an impact.

Table 5. Respondents' views of the characteristics of the main perpetrators and targets of workplace bullying among nurses

\begin{tabular}{lll}
\hline \multirow{2}{*}{ Variable } & Main perpetrators & Main targets \\
\cline { 2 - 3 } & $\mathbf{n}(\mathbf{\%})$ & $\mathbf{n}(\%)$ \\
\hline Gender & & \\
Female & $201(93.9)$ & $197(92.1)$ \\
Male & $13(6.1)$ & $17(7.9)$ \\
Cadre & & \\
Junior cadre & $1(0.5)$ & $180(84.1)$ \\
Middle cadre & $50(23.4)$ & $30(14.0)$ \\
Senior cadre & $163(76.2)$ & $4(1.9)$ \\
\hline
\end{tabular}

Table 6. Impact of workplace bullying among nurses

\begin{tabular}{|c|c|c|c|c|c|c|c|}
\hline Impact & $\begin{array}{l}\text { Strongly } \\
\text { Disagree }\end{array}$ & Disagree & Undecided & Agree & $\begin{array}{l}\text { Strongly } \\
\text { Agree }\end{array}$ & Mean & $\begin{array}{l}\text { Std } \\
\text { Dev }\end{array}$ \\
\hline Anger & $14(6.5)$ & $7(3.3)$ & $6(2.8)$ & $79(36.9)$ & $108(50.5)$ & 3.21 & 1.10 \\
\hline Anxiety & $15(7.0)$ & $19(8.9)$ & $45(21.0)$ & 89 (41.6) & $46(21.5)$ & 2.62 & 1.13 \\
\hline Depersonalization (I treat my patients as non-human) & $75(35.0)$ & $70(32.7)$ & $39(18.2)$ & $23(10.7)$ & $7(3.3)$ & 1.14 & 1.11 \\
\hline Emotional outburst or shutdown & $35(16.4)$ & $21(9.8)$ & $33(15.4)$ & $105(49.1)$ & $20(9.3)$ & 2.25 & 1.25 \\
\hline Frustration & $24(11.2)$ & $31(14.5)$ & $33(15.4)$ & $90(42.1)$ & $36(16.8)$ & 2.39 & 1.24 \\
\hline Headache/Migraine & $21(9.8)$ & $26(12.1)$ & $47(22.0)$ & 99 (46.3) & $21(9.8)$ & 2.34 & 1.12 \\
\hline I dread going to work & $35(16.4)$ & $54(25.2)$ & $31(14.5)$ & $73(34.1)$ & $21(9.8)$ & 1.96 & 1.28 \\
\hline $\begin{array}{l}\text { I take some days-offs to debrief because of emotional trauma } \\
\text { associated with bullying }\end{array}$ & $56(26.2)$ & $65(30.4)$ & $39(18.2)$ & 39 (18.2) & $15(7.0)$ & 1.50 & 1.25 \\
\hline I wish to be posted to another ward/unit & $25(11.7)$ & $45(21.0)$ & $54(25.2)$ & $64(29.9)$ & $26(12.1)$ & 2.10 & 1.21 \\
\hline $\begin{array}{l}\text { Increased incidence of stress related diseases like cardiac } \\
\text { arrhythmias hypertension etc. }\end{array}$ & $38(17.8)$ & $43(20.1)$ & $56(26.2)$ & $56(26.2)$ & $21(9.8)$ & 1.90 & 1.25 \\
\hline Indifferent: It does not affect me in any way & $46(21.5)$ & $80(37.4)$ & $28(13.1)$ & 42 (19.6) & $18(8.4)$ & 1.56 & 1.26 \\
\hline Inferiority complex & $44(20.6)$ & $45(21.0)$ & $51(23.8)$ & $58(27.1)$ & $16(7.5)$ & 1.80 & 1.25 \\
\hline Intention to leave the nursing profession & 81 (37.9) & $42(19.6)$ & $30(14.0)$ & $30(14.0)$ & $31(14.5)$ & 1.48 & 1.47 \\
\hline $\begin{array}{l}\text { Intention to travel abroad to practice nursing because I feel that } \\
\text { there will be less workplace bullying among nurses there }\end{array}$ & 35 (16.4) & 27 (12.6) & $28(13.1)$ & $52(24.3)$ & $72(33.6)$ & 2.46 & 1.47 \\
\hline It makes me to lack assertiveness & 34 (15.9) & 39 (18.2) & $59(27.6)$ & 59 (27.6) & $23(10.7)$ & 1.99 & 1.24 \\
\hline It makes me inflexible and rigid & $35(16.4)$ & $45(21.0)$ & $46(21.5)$ & $62(29.0)$ & $26(12.1)$ & 2.00 & 1.28 \\
\hline $\begin{array}{l}\text { It enables me to have better self-control in handling relationships } \\
\text { with colleagues }\end{array}$ & $21(9.8)$ & $31(14.5)$ & $41(19.2)$ & $86(40.2)$ & 35 (16.4) & 2.39 & 1.20 \\
\hline Job dissatisfaction & $30(14.0)$ & 59 (27.6) & $20(9.3)$ & 72 (33.6) & $33(15.4)$ & 2.09 & 1.34 \\
\hline Low self-esteem & $34(15.9)$ & $58(27.1)$ & $34(15.9)$ & $71(33.2)$ & $17(7.9)$ & 1.90 & 1.25 \\
\hline Medication errors and other mistakes while working & $42(19.6)$ & 76 (35.5) & $33(15.4)$ & $44(20.6)$ & $19(8.9)$ & 1.64 & 1.26 \\
\hline Offender behavior & $42(19.6)$ & $62(29.0)$ & $44(20.6)$ & $59(27.6)$ & $7(3.3)$ & 1.66 & 1.17 \\
\hline Poor concentration and forgetfulness while working & $42(19.6)$ & $57(26.6)$ & $33(15.4)$ & $65(30.4)$ & $17(7.9)$ & 1.80 & 1.28 \\
\hline $\begin{array}{l}\text { Poor working relationship as a team between me and my } \\
\text { colleagues }\end{array}$ & $35(16.4)$ & 37 (17.3) & $28(13.1)$ & $90(42.1)$ & $24(11.2)$ & 2.14 & 1.30 \\
\hline Sleep disturbances & 39 (18.2) & $60(28.0)$ & $31(14.5)$ & $71(33.2)$ & $13(6.1)$ & 1.81 & 1.25 \\
\hline Strained social relationships with colleagues & $24(11.2)$ & $35(16.4)$ & $31(14.5)$ & $99(46.3)$ & 25 (11.7) & 2.31 & 1.21 \\
\hline Victim behavior; I feel powerless to change my situation & 29 (13.6) & $51(23.8)$ & $55(25.7)$ & $50(23.4)$ & $29(13.6)$ & 2.00 & 1.25 \\
\hline Overall Mean & & & & & & 2.02 & 1.31 \\
\hline
\end{tabular}




\section{Discussion}

\subsection{Workplace bullying as perceived by nurses}

Workplace bullying has been found to exist at considerable levels in almost all workplaces of nurses. Findings of this study brought to light the existence and high prevalence of workplace bullying among nurses working in tertiary hospitals in Enugu, southeast Nigeria. Tables 2-4 show that majority of the nurses did not only affirm the existence of workplace bullying among the nurses in their hospitals, wards/units, they also indicated that they have had first-hand experience of workplace bullying among nurses either as victims/targets and have also witnessed the bullying of others. The female dominance of the nursing workforce in these hospitals as shown in Table 1 (socio-demographic characteristics of respondents) seems to be a major factor in the high prevalence of workplace bullying recorded in this study. This is because of the inherent tendencies for females to bully other females as explained by the theories of relational aggression and oppression.

Majority of the nurses do not also have sufficient information with regards to what constitutes workplace bullying. The significant disparity in the response of the nurses to mere questions about workplace bullying and that on the modified NAQ justifies this finding. Majority of the respondents (73\%) reported that had been victims of workplace bullying among nurses. A higher percentage (91\%) also indicated that they were victims on weekly basis after a definition of workplace bullying was given as shown in Table 4 but when asked to identify the negative behaviors which they experienced from other nurses within the last six months as listed on the modified NAQ, there was a reasonable reduction in the percentage of the respondents $82.6 \%$ was recorded. This shows that although nurses report a high occurrence of workplace bullying, the actual occurrence based on the NAQ (which is a more objective tool) is much lower, suggesting a poor knowledge of what constitutes workplace bullying among the nurses. It is also a possibility that some of the nurses may also experience workplace bullying without knowing it since they do not know the behaviors that constitute workplace bullying as well as the forms in which workplace bullying is perpetrated. Poor knowledge of what constitutes workplace bullying among nurses may possibly be attributed to the lack of or inadequate education of the nurses in this regard by nurse leaders, nurse educators and nursing regulatory bodies.

Furthermore, majority of the victims of workplace bullying among nurses did not report their bullying experiences to the authorities. Possible reasons why nurses do not report incidence of bullying may include; not knowing where and who to report to, insufficient information about; what constitutes workplace bullying, right of victims to report and provisions for punishment for offenders. Additionally, the culture or silence among nurses, absence of a functioning disciplinary committee to handle cases of bullying and not willing to be considered a trouble maker ${ }^{[3]}$ may affect the level of reporting of workplace bullying since many perpetrators in most cases are senior nurses. This finding is not surprising since nothing much has been done by nurse leaders, nursing labour unions, hospital management and the nursing and midwifery council of Nigeria with regards to educating nurses about workplace bullying, formulating and enforcing measures to protect nurses from workplace bullying as well as punish the perpetrators. Insufficient reporting of cases of workplace bullying by victims could also contribute to the high prevalence of workplace bullying among nurses working in these hospitals since adequate evidence of its level of existence and prevalence is required to enable the authorities to act.

\subsection{Workplace bullying behaviors based on the modified negative acts questionnaire}

The findings of this study shows that females have a high tendency to engage in psychological form of bullying (gossiping, back-biting, formation and exclusion of other females from social cliques, etc.). Majority of the respondents indicated that they have observed the negative behaviors listed in the modified NAQ from one or more other nurses on daily basis in the past six months. Some of the negative behaviors commonly observed by the respondents include; gossiping, backbiting and failure to respect the other nurse's privacy. Excessive workload without supervision, humiliating someone in front of others including patients and unfair allocation of job and postings were also commonly reported by the respondents. The non-physical nature of the negative behaviors identified by the respondents on the modified NAQ show that females have a higher tendency to engage in non-physical forms of bullying like psychological, verbal and cyber than they do engage in the physical type(slapping, hitting). The occurrence of these negative behaviors among nurses has a high tendency to affect the health, interpersonal and work relationship among the respondents.

\subsection{Extent of weekly experience of workplace bullying among nurses working in tertiary institutions in Enugu State}

This study shows that although workplace bullying exists and is highly prevalent among nurses working in tertiary hospitals in Enugu, it does not occur frequently. Data in Table 3 show that although $82.6 \%$ of the respondents identified being on the receiving end of the behaviors on the modified NAQ, the highest daily occurrence of the most frequently observed behavior was recorded by $22 \%$ of the respondents. 
Majority of them indicated that they observed the behaviors occasionally. Data in Table 4 also show that majority of the respondents experienced the trend only occasionally and seldom. This result notwithstanding, efforts (education, conflict resolution and punishment of offenders) should be made to reduce to the barest minimum the incidence of workplace bullying since a minute incidence is enough to jeopardize interpersonal and work relationships among team members.

\subsection{Respondents' view of the characteristics of the main perpetrators and targets of workplace bullying among nurses}

This study unveils that female nurses are the main perpetrators as well as the main targets of workplace bullying among nurses. The inherent tendencies of females to bully persons of the same gender because of relational aggression may explain this. Female perpetrators of workplace bullying are thus most likely to bully other females. Consequently, the high female dominance of the nursing workforce paves way for the high prevalence of workplace bullying among nurses recorded in these hospitals.

Additionally, the study also reveals that nurses in the senior cadre are the main perpetrators of workplace bullying while those in the junior cadre are the main targets/victims. One wonders if oppression as explained by oppressed group model is a factor. ${ }^{[13]}$ Since oppressed people are highly oppressive, ${ }^{[12]}$ there is a high tendency for nurses who had been victims workplace bullying in the past to become future perpetrators as they progress in their career. The hierarchical nature of nursing profession may also permit senior nurses to hide under hierarchical structure to perpetrate workplace bullying. Information obtained from the study show that the number of the perpetrators increased significantly with increase in the cadre of the nurses, the number of the target was also observed to increse down the hierachical ladder. This justifies the relationship between the prevalence of bullying and the cadre of nurses. Another factor is that it may be more convenient to bully junior nurses than the senior ones. Furthermore, over the years as nurses spend more years in the profession they may get used to workplace bullying among nurses and report less of it. ${ }^{[1]}$ In other words, the gender and cadre of the nurses working in tertiary hospitals in Enugu is significantly associated to the prevalence of workplace bullying among nurses.

\subsection{Impact of workplace bullying among nurses}

Social and work relationship among colleagues in the health sector play a significant role in the quality of care provided. Indeed to ensure quality care, nurses must communicate effectively. Workplace bullying among nurses has consid- erable impact on the general health, work performance and retention rate of nurses. The common impact of workplace bullying identified by the respondents include; anger, anxiety, poor working relationship among colleagues/team members, frustration and job dissatisfaction. Findings from this study also shows that workplace bullying among nurses have greater impact on the psychological and social well being of the respondents than on the quality of care they deliver.The study revealed that the more nurses are exposed to workplace bullying the less the social relationships and communication among them. ${ }^{[13]}$ In addition, majority of the nurses expressed an intention to travel abroad to continue their practice in nursing. This shows that workplace bullying is one of the reasons why Nigerian nurses travel abroad (especially US, UK and Canada) to practice nursing. Nigeria has been listed as one among the five top countries that export nurses. ${ }^{[22]}$ The respondents have the impression that the prevalence of workplace bullying among nurses is less abroad than in Nigeria. It is also a possibility that the respondents believe that the supposed better working condition in most hospitals in the developed countries will help reduce the incidence of workplace bullying. A major inference to be drawn here is that majority of them lack adequate information about the phenomenon to appreciate that it existed in almost all workplaces of nurses irrespective of geographical location ${ }^{[15,19]}$ although the incidence may be lower there because of better awareness and implementation of policies to curb workplace bullying among nurses in these developed countries. ${ }^{[14]}$

\section{Conclusion}

Workplace bullying occurs among nurses working in tertiary hospitals in Enugu. Although a high prevalence of workplace bullying is reported among nurses, a lower prevalence is recorded on the modified NAQ due to poor knowledge of the nurses of what constitutes workplace bullying. Poor knowledge of what constitutes workplace bullying among nurses in addition to relational aggression and oppression among females are major contributors to the prevalence and outcome of workplace bullying among nurses working in tertiary hospitals in Enugu Southeast Nigeria. Workplace bullying does not also occur frequently among nurses and majority of the victims do not report the incidence to the authorities. The gender and cadre of nurses have a significant relationship with the number of nurses who are perpetrators and targets of workplace bullying. The main perpetrators of workplace bullying are female nurses in the senior cadre while the main targets are female nurses in the junior cadre. Female nurses working in tertiary hospitals in Enugu engage more in psychological form of bullying than other forms of bullying (physical and cyber). The most commonly expe- 
rienced workplace bullying behaviors which the nurses observed within the six month period prior to the study,include; gossiping, backbiting, excessive workload without supervision, failure to respect the other nurse's privacy, humiliating someone in front of others including patients, and unfair allocation of jobs and postings. Nonetheless, workplace bullying has considerable impact on the health and general performance of nurses. The impact of workplace bullying is more on the personal health, social and work relationship of the nurses than on the nurses' interpersonal relationship with their patients and the quality of care they deliver. Major impact of workplace bullying as identified by the nurses are; anger, anxiety, poor working relationship among colleagues/team members, frustration and job dissatisfaction. In addition, workplace bullying is a major reason why majority of the nurses working in tertiary hospitals in Enugu would wish to travel abroad to practice nursing. Thus the nurses would wish to continue with nursing practice given a better work environment.

To reduce the prevalence and impact of workplace bullying among the nurses, it is recommended that thorough education be given to all nurses working in these hospitals and beyond about what constitutes workplace bullying. Methods of communicating effectively and respectfully among themselves should also be stressed. Nurse leaders and hospital administrators should not only constitute functional disciplinary committees in all the tertiary hospitals in Enugu, victims should be encouraged to report the incidence as well. Nurses who report incidences of workplace bullying should be protected from further attacks by the bully. Furthermore, frantic efforts should also be made to identify and punish the perpetrators to serve as a deterrent to others. Mediation and reconciliation programmes should also be held to intervene and make peace between nurses whose relationships have been affected by workplace bullying to ensure peaceful and adequate communication among them. Different results may be obtained if more of the senior nurses than the junior ones participated in the study. Further studies should also be carried out to find out the prevalence of workplace bullying among nurses in other regions of Nigeria as well as in other hospitals with higher number of males than females.

\section{CONFLICTS OF INTEREST Disclosure}

The authors declare that there is no conflict of interest.

\section{REFERENCES}

[1] Stelmaschuk S. Workplace bullying and emotional exhaustion among registered nurses and non-nursing, unit based staff. A senior Honors thesis presented in partial fulfillment of the requirements for the degree of Bachelor of Science in nursing. Ohio: 2010.

[2] Jahner J. Building Bridges: An Inquiry into Horizontal Hostility in Nursing Culture and the use of Contemplative Practices to Facilitate Cultural Change. 2011.

[3] Carter M, Thopson N, Crampton P, et al. Workplace bullying in the UK NHS: A questionnaire and interview study on prevalence, impact and barriers toreporting. 2003.

[4] Phelps C, Wilson B. JONA's Healthcare Law. Ethics and Regulation. 2013; 15(1): 51-57. PMid:23429651 http://dx.doi.org/10.10 97/NHL . Ob013e3182861503

[5] Ahliquist E, Riehl G. Managing Lateral Violence and its impact on the team: Nurses and Students. 2013.

[6] Berman A, Synder S. Erb's Fundamentals of Nursing Concepts, Process and Practice (9th Edition), New Jersey: Pearson Publishers; 2012.

[7] Einarsen S. The nature, causes and consequences of bullying at work: The Norwegian experience. 2000.

[8] Ikyanyon D, Ucho A. Workplace bullying, job satisfaction and job performance among employees in a federal hospital in Nigeria. European Journal of Business and Management. 2013; 5(23): 116-123.

[9] Department of Education and Early Childhood Development. What is Bullying? 2013.

[10] Ezeruigbo C. Types and impact of violence against nurses in a nonpsychiatric/mental hospital in Nigeria. 2012.

[11] Workplace Bullying Institute. US Workplace Bullying Survey. 2007.
[12] Thompson D. A discussion of the problem of horizontal hostility. 2003.

[13] Pupora C, Blegen M. Horizontal violence and the quality and safety of patient care: A conceptual model Published online. Nursing Research and Practice Journal. 2012; 10(1155): 1-10. PMid:22655187 http://dx.doi.org/10.1155/2012/306948

[14] Rocker CF. Addressing Nurse-to-Nurse Bullying to Promote Nurse Retention. American Nurses Association (ANA Periodicals). 2008; 13(3): 08.

[15] Mckenna B, Smith NA, Suzette P, et al. Horizontal violence: Experiences of Registered Nurses in their first year. Journal of Advanced Nursing. 2003; 42(1): 90-96. http://dx.doi .org/10.1046/j.1 $365-2648.2003 .02583 . x$

[16] MacKusick CI, Minick P. Why Are Nurses Leaving? Findings from an Initial Qualitative Study on Nursing Attrition. Medsurg Nursing. 2010; 19(6): 335. PMid:21337990

[17] Bartholomew K. Ending Nurse-to-Nurse Hostility: Why nurses eat their young and each other, Marblehead, MA: HCPro, Inco, 2006.

[18] HCPro. A closer look at nurse-to-nurse hostility: Strategies for Nurse Managers Benchmarking.com. 2013.

[19] Capitulo K. Combating disruptive behaviors: Strategies to Promote a Healthy Work Environment. The Online Journal of Issues in Nursing (ANA Periodicals). 2009.

[20] National Population Commission. National Population Commission's Population Figures For Nigeria States for 2006 Population and Housing Census. 2006.

[21] Schroeder M, Hollis M. Workplace Bullying Among Registered Nurses. 2013. 
[22] Walker J. The Global Nursing Shortage: Migration, Brain Drain and Going Forward. Johns Hopkins School of Nursing magazine. 2010.

[23] Einarsen S, Hoel H, Notelaers G. Measuring bullying and harassment at work: Validity, factor structure and psychometric properties of the negative acts questionnaire. Work \& Stress. 2009; 23(1): 24-44. http://dx.doi.org/10.1080/02678370902815673

[24] Karatza C, Zyga S, Tziaferi S, et al. Workplace bullying and general health status among nursing staff of Greek Public Hospital. Annals of General Psychiatry. 2016. PMid:26949408 http://dx . doi .org /10.1186/s12991-016-0097-z 